\title{
Estado democrático desenvolvimentista e desenvolvimento endógeno
}

\author{
Development democratic state and endogen development
}

\section{Paulo Eduardo Panassol}

\author{
Doutorando em Economia do Desenvolvimento pelo PPGE-UFRGS \\ Auditor Público Externo do Tribunal de Contas do Estado do Rio Grande do Sul (TCE-RS) \\ paulo.panassol@ufrgs.br \\ ppanassol@gmail.com
}

Resumo: Esse artigo se caracteriza como uma pesquisa exploratória, tendo como método o estudo bibliográfico, visando compreender o processo de desenvolvimento endógeno em um país periférico como o Brasil, a partir da perspectiva de Celso Furtado, tendo em vista a sua contribuição diferenciada em termos de rigor metodológico e da liberdade de pensar, do papel do Estado, além de apresentar alguns "guias" de política. Depreende-se da pesquisa realizada que, para a superação do subdesenvolvimento e alcance da homogeneização social, deve-se promover o desenvolvimento endógeno com base num Estado democrático desenvolvimentista, devendo o cientista abandonar as explicações cômodas oriundas de doutrinas amparadas no reducionismo econômico que não levam em conta os problemas que corroem o organismo social.

Palavras Chaves: Desenvolvimento; Desenvolvimento Endógeno; Estado Democrático Desenvolvimentista.

\begin{abstract}
This article is characterized as an exploratory research, using the bibliographic study as a method, aiming to understand the endogenous development process in a peripheral country like Brazil, from the perspective of Celso Furtado, in view of his different contribution in terms of rigor methodological and freedom of thinking, the role of the State, in addition to presenting some policy "guides". It appears from the research carried out that, in order to overcome underdevelopment and reach social homogenization, endogenous development based on a democratic developmental state must be promoted, and the scientist must abandon comfortable explanations originating from doctrines supported by economic reductionism that do not lead taking into account the problems that erode the social organism.
\end{abstract}

Keywords: Development, Endogenous Development, Developmental Democratic State. 


\section{Introdução}

Os últimos 40 anos foram de transformações profundas na economia brasileira. As mudanças causadas pelo regime de acumulação capitalista, pela globalização e pela revolução da tecnologia da informação e comunicação impactaram sobremaneira seu desenvolvimento econômico, social e político.

De um lado, o país adotou práticas de livre comércio de bens e serviços e passou por mudanças estruturais decorrentes da nova divisão internacional do trabalho, calcada na retorialização da produção e na inserção nas cadeias globais de valor, culminando numa desindustrialização precoce.

Por outro lado, adotou a liberalização dos fluxos internacionais de capitais, que junto das inovações financeiras e da revolução tecnológica, o tornaram mais suscetível à intensa instabilidade financeira, à volatilidade do investimento internacional e às crises recorrentes, típicas do modo de acumulação capitalista. ${ }^{1}$

Preocupado com a realidade, com os problemas sociais e com o processo de desenvolvimento do Brasil, Celso Furtado se mostrava indignado quanto à limitação do poder explicativo das teorias tradicionais de desenvolvimento econômico em relação à especificidade do subdesenvolvimento. Tal ponderação ainda deve estar presente nas reflexões daqueles que pretendem entender o atraso econômico e, sobretudo, a miséria social do país. Devem ser considerados, também, os possíveis caminhos a serem trilhados para a retomada do desenvolvimento.

Esse artigo, por meio de pesquisa bibliográfica, visa compreender o processo de desenvolvimento endógeno em um país periférico como o Brasil, a partir da perspectiva de Celso Furtado, tendo em vista a sua contribuição diferenciada em termos de rigor metodológico e da liberdade de pensar, do papel do Estado, além de apresentar alguns "guias" para a ação política com inspiração furtadiana.

Além dessa introdução, o artigo é dividido em mais quatro seções. A segunda parte traz aspectos selecionados do pensamento de Furtado que o inquietavam e que guiaram a sua produção teórica e atuação como homem público republicano. A terceira seção trata do referencial teórico sobre o desenvolvimento endógeno e o papel do

\footnotetext{
1 A presente crise econômica, que teve início com a pandemia do Covid-19, é de natureza diferente daquela da Grande Recessão, iniciada com a quebra do banco Lehman Brothers, em setembro de 2008: é uma crise no lado real da economia, a partir de choques adversos de demanda e de oferta. Sua extensão e efeitos ainda estão sendo escritos pela História e são, em certa medida, por essa natureza, desconhecidos.
} 
Estado na sua promoção. Na quarta parte, são apresentados alguns guias de políticas para ação prática, a partir da leitura da obra furtadiana. Por fim, a quinta seção trata das principais conclusões desse artigo.

\section{Referencial teórico furtadiano: Liberdade Para Pensar, Rigor Metodológico}

As teorias do desenvolvimento econômico passaram a ter relevo político e social após a Segunda Guerra Mundial, tendo em vista os esforços de reconstrução dos países afetados pelo conflito, a partir de uma agenda econômica pró-crescimento, via organismos internacionais como a Organização das Nações Unidas (ONU), a Organização Mundial do Comércio (OMC) e o Banco Mundial. Por trás também estava uma agenda política anticomunista e antissocialista, que via na promoção do desenvolvimento dos países periféricos a formação de uma rede de aliados aos Estados Unidos.

Nesse contexto, aos países latino-americanos se conformava a oportunidade de superação do baixo desempenho econômico e do subdesenvolvimento a partir do redesenho de novas relações econômicas e da inserção internacional. O caminho seria via coordenação e promoção por Estados intervencionistas, em boa parte do tempo e lugares, autoritários e nacionalistas (CHANG, 2004; NIEDERLE, RADOMSKY, 2016).

Com relação ao pensamento tradicional da época, Niederle e Radomsky (2016: 7) referem que as teorias do desenvolvimento eram "simplistas e baseadas em diagnósticos comprometidos com a ideologia do progresso, [sustentando] que os países subdesenvolvidos precisavam passar de um estágio tradicional a um estágio moderno através de inúmeras etapas intermediárias".

Nessa quadra, Celso Furtado é entendido como um dos pioneiros da denominada "teoria moderna do desenvolvimento" junto de Rosenstein-Rondan, Prebisch, Singer, Lewis, Nurkse, Myrdall e Hirschman (BRESSER-PEREIRA, 2001). Foi um economista que pensou o desenvolvimento em termos das especificidades de países periféricos como o Brasil, com fundamento no método histórico-estrutural, a partir de observação da realidade econômica, aliando teoria com ação política, visando vencer nosso atraso também em termos das malformações sociais. 
Todavia, longe de ser um autor consensual, o pensamento de Celso Furtado oscila da aceitação plena à recusa formal de suas teses (CEPÊDA, 2003), não ocupando papel de destaque nos cursos de Economia em disciplinas que versam sobre desenvolvimento econômico, excetuando-se sua obra de referência, Formação Econômica do Brasil (ALMEIDA FILHO, 2008). No entanto, para Oliveira (2001: 2), o pensamento de Furtado passou “(...) pela difícil prova de [tornar-se] referência para movimentos políticos, formatando políticas e influenciando as gerações (...) [e] no sentido gramsciano, poucas são as obras que se transformam em representações da realidade".

Cepêda (2003) afirma que a obra de Celso Furtado possui três fases: a “otimista", cujos trabalhos, datados do início de sua carreira até 1964, versaram sobre os limites da herança colonial ao desenvolvimento do país, mas, ainda assim, haveria a possibilidade do "salto para a modernização"; a segunda fase, de "pessimismo espantado", iniciou-se com a cassação política e foi até os anos 1970, caracterizando-se pelo "sentimento de derrota" e que regimes fechados, como o que vigorava na época no país, levariam ao estrangulamento econômico; por fim, na terceira fase, de "crítica renitente", Furtado introduziu o conceito de modernização do subdesenvolvimento. Ainda para essa autora, os trabalhos da primeira fase "provocaram um maior impacto no pensamento social brasileiro e (...) constituem a espinha dorsal do raciocínio furtadiano" (CEPÊDA, 2003: 3).

Insatisfeito com a teoria dominante, refere Furtado (1977: 9):

Um quarto de século tateando os labirintos das teorias econômicas e esforçando-me para descobrir relações entre os ensinamentos que daí se derivam e os problemas práticos de nossa época, convenceu-me sobejamente da insuficiência do quadro conceitual com que trabalhamos nessa ciência. Um prolongado esforço para compreender os problemas históricos de desenvolvimento e subdesenvolvimento, apoiado nos instrumentos da análise econômica, levou-me à convicção de que a elaboração de uma "dinâmica econômica" que seja algo mais do que uma série de exercícios engenhosos para distração de professores universitários, é objetivo inalcançável dentro do quadro de referência em que trabalhamos. 
Nessa passagem consegue-se depreender alguns dos elementos que marcam o pensamento de Celso Furtado e que o ajudaram a compreender o processo do atraso econômico e social do Brasil: o inconformismo com o saber econômico convencional; o método histórico-estrutural para entender a realidade em que estão inseridas as sociedades; e, a análise do desenvolvimento e do subdesenvolvimento a partir da relação dual centro-periferia.

\subsection{Inconformismo com o saber convencional}

Para Furtado, desde o século XIX, se buscava por “[...] uma ciência econômica pura, ou seja, com validade explicativa independentemente do conhecimento das estruturas sociais" (FURTADO, 1977: 17; grifos originais). Conforme o autor, muito esforço foi despendido para o desenvolvimento de instrumentos de trabalho para a Ciência Econômica, como a Matemática e a Econometria, embora os resultados tivessem sido "modestos". Baseada nos meios, esse modo de fazer ciência aparentava exatidão e objetividade por abordar problemas expressos em termos quantitativos, dessa forma, poderiam ser isolados do seu contexto social (FURTADO, 1974, 1977).

A fixação nesses instrumentos de apoio, portanto nos meios, leva o economista a acreditar em "vacas sagradas" como a condição "ceteris paribus", a "soberania do consumidor", a entender o agregado macroeconômico poupança como se fosse homogêneo, e a utilizar conceitos "ambíguos" que não possuem uma exata significação, como o do Produto Interno Bruto (PIB) e o da taxa de crescimento do PIB. Em tais conceitos estão implícitos custos sociais e ecológicos elevados e crescentes, contudo tais dimensões não são levadas em consideração quando de seus cálculos (FURTADO, 1974).

Conforme Furtado, a Economia é uma ciência social e, como tal, tem como objeto de estudo os problemas da sociedade, portanto, o economista deve ter uma visão dinâmica global das suas estruturas, incluindo os sistemas de decisão, as estruturas de poder, os conflitos e as lutas que são decisivos para a sua evolução (FURTADO, 1977). Para o autor, dever-se-ia buscar uma "teoria social global", não uma junção de saberes, mas uma teoria que "[entronque] a teoria da reprodução da população, a teoria das decisões intertemporais (acumulação), a teoria da estratificação social e a teoria do 
poder" (FURTADO, 1977: 11). Dessa forma, não se deve aplicar à Economia o princípio da causalidade oriundo das ciências físicas “[...] que utiliza funções analíticas (contínuas) por definição inadequadas para descrever as descontinuidades inerentes à realidade social" (FURTADO, 1978: 171).

Por outro lado, influenciado por Karl Mannheim (1960), Furtado entendia que o esforço de reconstrução institucional, nas suas dimensões econômica, política, social e cultural, deve se dar pelo planejamento, por meio da racionalidade no nível dos meios e dos fins, como forma para a superação do subdesenvolvimento, visando a preservação da liberdade dos homens (FURTADO, 2001, 2014).

Também orientava a postura propositiva de Furtado o conceito de utopia de Mannheim no sentido de, a partir da compreensão dos problemas histórico-sociais e assentado em bases democráticas, tentar transformar tal realidade pela ação. Conforme esse autor, são "utópicas somente aquelas orientações que, transcendendo a realidade, tendem, a se transformarem em conduta, a abalar, seja parcial ou totalmente, a ordem de coisas que prevaleça no momento" (MANNHEIM, 1968: 144).

Assim, Furtado estabelece um arcabouço teórico independente, tendo por objeto o entendimento da realidade econômica e social dos países latino-americanos, bem como reflete sobre medidas de superação para tais problemas, como a convicção na técnica do planejamento para coordenar as decisões econômicas, no desenvolvimento da pesquisa científica e tecnológica nas nações periféricas e na ação do Estado em função das prioridades sociais. Frisa-se, conforme Furtado (1999), que o planejamento é a grande invenção do capitalismo e deve ser utilizado para tornar eficaz o processo de formação de capital, contudo não deve ser utilizado para destruir as bases da criatividade social. Tal instrumento deve estar a serviço de uma política de modificação das malformações estruturais econômicas e, sobretudo, das sociais.

\subsection{0 método histórico-estrutural}

Furtado (1977) afirmava que outro caminho enveredado pelos economistas, nas análises econômicas tradicionais, foi a utilização de métodos a-históricos que os distanciavam da visão global da História. Segundo o autor, na medida que os analistas se aprofundavam em instrumentos metodológicos aperfeiçoados como as noções dos 
equilíbrios parcial ou geral, incapacitavam-se em captar fenômenos sociais que, por definição, estão sempre em desenvolvimento (FURTADO, 1964).

Para tanto, Furtado fazia uso do método histórico-estrutural como meio para interpretar a realidade latino-americana e do Brasil, em específico. Afirmava que o ponto de partida para a compreensão do desenvolvimento é a apreensão da realidade social, vista a partir de suas estruturas que evoluem ao longo do tempo (FURTADO, 1981).

A História é, portanto, elemento fundamental na teoria do desenvolvimento econômico de Furtado, bem como no estudo dos processos de evolução social dos países da América Latina, incluindo o Brasil. Para Bresser-Pereira (2001: 11), Furtado “[...] não narra a história da economia brasileira, ele a analisa. Ninguém fez com mais brilho o uso da teoria econômica para entender a evolução da economia brasileira do que Furtado em Formação Econômica do Brasil”.

Em diversas passagens da obra de Celso Furtado podem-se encontrar referências à centralidade da História na formação de seu pensamento. Esse autor " [...] considerava a economia como um instrumento para penetrar no social e no político, e avançar na compreensão da História, particularmente quando esta ainda se exibia como presente a nossos olhos" (FURTADO, 2014: 15).

Segundo Furtado, a Ciência Econômica era instrumental e o permitia “[ [... com maior eficácia, tratar problemas que [...] vinham da observação da história ou da vida dos homens em sociedade" (FURTADO, 1972a: 22; grifos originais). Afirmava, ainda, que "[...] era possível montar um modelo com perspectiva histórica multissecular da economia brasileira [...] [captando] o evolver histórico no quadro de relações estruturais" (FURTADO, 2001: 16).

Furtado asseverava que fora tomado da obsessão de estudar a economia do Brasil e de descobrir as causas do seu atraso. Para tanto, as causas deveriam ser buscadas, de maneira analítica, na história e nas singularidades do seu processo formativo, não adiantando compará-la a modelos abstratos ou a modos de produção "pré-fabricados" (FURTADO, 2014).

Nesse sentido, a seguinte passagem presente no livro Obra Autobiográfica dá a dimensão da História, da independência de pensamento, da análise e da observação da realidade como elementos condutores de Furtado: 
Não é fácil aplicar a imaginação na descoberta do que é único no processo formativo de um sistema econômico. O professor Gudin me disse um dia, em tom de reprimenda: 'Você apela demasiadamente para a imaginação em suas análises. Devia ter sido romancista, e não economista'. Não cabe dúvida de que a imaginação descontrolada produz delírios, mas como conceber uma construção teórica sem um forte ingrediente de imaginação? Pelo fato mesmo de que são irreversíveis e comportam muito de aleatório, os processos históricos somente são compreendidos quando de alguma forma são reinventados. Daí que a capacidade analítica não seja suficiente para captar o que neles é essencial. Não se trata de fazer a teoria do particular, e sim de captar o que neste desborda do quadro explicativo convencional. Arregacei as mangas e comecei a pensar o Brasil com a desenvoltura de quem reunisse ignorância e intrepidez (FURTADO, 2014: 37; grifos nossos).

Assim, não basta uma leitura crítica das diversas teorias do desenvolvimento. Deve-se aprofundar o conhecimento empírico da realidade por meio da compreensão da dinâmica dos processos sociais, com isso, possibilitando o estabelecimento de uma teoria do subdesenvolvimento capaz de instrumentalizar políticas para a superação do atraso e, mais do que isso, para o alcance da homogeneização social.

\subsection{O subdesenvolvimento como objeto de análise}

A análise de Furtado do desenvolvimento e do subdesenvolvimento é tida como um marco do pensamento econômico e constitui uma inflexão frente aos fundamentos convencionais sobre o tema, que foram erguidos sobre as bases ortodoxas da corrente dominante, notadamente Rostow e sua teoria das etapas históricas do desenvolvimento econômico. $^{2}$ Esse autor propunha uma teoria dinâmica do desenvolvimento baseada na observação das sociedades, vinculada ao crescimento econômico que tem por base a industrialização e que essa levaria à modernização (ROSTOW, 1964).

\footnotetext{
${ }^{2}$ A respeito da análise da evolução histórica da teoria do desenvolvimento, Furtado insere o exame que faz do pensamento de Rostow na terceira parte do seu clássico livro Teoria e Política do Desenvolvimento Econômico, de 1983.
} 
Por outro lado, Prebisch (1949) chamou a atenção para a questão do subdesenvolvimento, a partir da deterioração dos termos de intercâmbio que acabava por gerar trajetórias dualistas entre as economias centrais, industrializadas, e os países periféricos, produtores de matérias primas e de bens primários. Para tanto, necessitavase de uma formulação teórica independente, distinta daquela que fora pensada para os países do centro.

Nesse sentido, Myrdal (1968) entende como inadequada a teoria tradicional do comércio internacional que não serve para tratar, em termos causais, das desigualdades econômicas entre nações e em termos regionais dentro dos países, pois não foi elaborada para explicar a realidade do desenvolvimento e do subdesenvolvimento. Tal teoria é centrada apenas em fatores econômicos, e para uma completa análise da realidade social os aspectos "não econômicos" devem ser considerados, eis que os sistemas sociais são fenômenos de causas múltiplas que estão inter-relacionados em processos de causação circular.

Embora a concepção teórica original tivesse sido formulada por Prebisch (BIELSCHOWSKY, 1998: 4), foi com uma "mais abrangente e aprofundada elaboração" realizada por Celso Furtado que se desenvolveu plenamente o conceito de subdesenvolvimento, tido como uma formação singular do capitalismo com poder explicativo da especificidade latino-americana “[...] e não como um elo na cadeia do sequenciamento que vai do não-desenvolvido ao desenvolvido [...]" (OLIVEIRA, 2000: 121).

Na mesma linha, Conceição Tavares (2000: 129) afirma que a concepção de Furtado é mais completa do que a noção centro-periferia de Prebisch, “[...] porque contempla a análise de nossa estrutura subdesenvolvida e a dinâmica da sua articulação interna-externa". Dado que o perfil da demanda interna é formado a partir da adoção de padrões de consumo do centro, portanto de níveis de renda em muito superiores às dos países da periferia, há um desequilíbrio na assimilação do progresso técnico a favor das inovações que incidem sobre o estilo de vida adotado, impedindo o surgimento de processos autossustentados e endógenos de desenvolvimento, perpetuando-se, assim, a heterogeneidade social e a restrição externa (TAVARES, 2000).

Ao contrário de Rostow, Furtado entende o subdesenvolvimento como um processo histórico autônomo e não como uma fase que necessariamente os países têm que cumprir para chegar ao desenvolvimento econômico no âmbito da formação das economias capitalistas. Para esse autor, as economias subdesenvolvidas possuem duas 
características essenciais: a heterogeneidade estrutural interna e o grau de dependência externa, a partir da adoção de estilos de vida dos países centrais (FURTADO, 1983, $2002 \mathrm{a}) .^{3}$

Furtado percebeu que "[...] o subdesenvolvimento requeria um esforço específico de teorização, e assim [elaborou] o [que] mais tarde ficou conhecido como teoria do subdesenvolvimento" (FURTADO, 2002b: 2; grifos originais). Mais, percebeu que não bastam crescimento da renda e modernização, consubstanciada em novas formas de vida imitadas de outras sociedades, sem benefício para a massa da população. O verdadeiro desenvolvimento vem da capacidade de fazer os homens agentes de transformação, de si mesmos e da sociedade em que vivem, realizando suas potencialidades em benefício da coletividade.

Segundo Furtado:

A formulação da teoria do subdesenvolvimento constitui, por si mesma, uma manifestação da tomada de consciência das limitações impostas ao mundo periférico pela divisão internacional do trabalho que se estabelece com a difusão da civilização industrial. O primeiro passo consistiu em perceber que os principais obstáculos à passagem da simples modernização ao desenvolvimento cimentavam-se na esfera social. (FURTADO, 1994a: 37$8)$.

Para Furtado (1992), a teoria do subdesenvolvimento aborda os processos sociais onde a elevação da produtividade e a propagação do progresso técnico, dado por novos produtos e por processos produtivos mais eficazes, que é inerente ao capitalismo, não conduzem à homogeneização social, em que pese possam elevar o nível de vida médio da população. ${ }^{4}$ Para o autor, o progresso tecnológico se introduz de início pelo lado da demanda, com a sociedade periférica se modernizando antes do desenvolvimento da economia (FURTADO, 2008). Todavia, o fator dinamizador das economias subdesenvolvidas é a importação de formas de consumo "imitadas" dos países centrais (FURTADO, 1983).

\footnotetext{
${ }^{3}$ Celso Furtado afirmava que a insegurança social, marcada pelo subdesemprego, pelo desemprego disfarçado e pela marginalidade social, é uma característica estrutural das economias subdesenvolvidas (FURTADO, 1977).

${ }^{4}$ Segundo Furtado (2001: 58), o problema que "mais o apaixonou" foi o de encontrar explicações para a elevação do nível de renda e o avanço da industrialização ocorrida no Brasil que, no entanto, não se traduziram na redução da heterogeneidade social.
} 
Conforme Furtado (2001), a inserção dos países periféricos no sistema de divisão internacional do trabalho se baseia na dependência tecnológica associada à adoção de padrões alienígenas de consumo, característica do desenvolvimento desigual do capitalismo. A reprodução de tal padrão de consumo e os privilégios das minorias com seus estilos de vida foram chamados por Furtado de "mimetismo cultural".

Portanto, para que ocorram processos endógenos de desenvolvimento autossustentados, necessita-se controlar o processo de inovações tecnológicas de tal forma que o desenvolvimento das forças produtivas seja consentâneo com os padrões de consumo. Tal desiderato seria alcançado com o estabelecimento ou com a ressignificação da cultura nacional, consubstanciada numa estratégia da coletividade, vindo a transformar o país a partir de dentro.

\section{Desenvolvimento endógeno e o papel do Estado}

\subsection{Desenvolvimento endógeno para o alcance da homogeneização social}

Conforme Furtado (2008: 127), “em nenhum campo dos estudos econômicos o embasamento ideológico é tão visível como na chamada teoria do desenvolvimento". Conforme a concepção furtadiana, desenvolvimento econômico é um processo de transformação que engloba o conjunto da sociedade por meio da utilização de métodos mais eficazes na acumulação das forças produtivas, na introdução de novos bens e serviços à disposição da coletividade, bem como na satisfação plena das necessidades humanas.

Celso Furtado distingue as relações que existem entre o desenvolvimento e o conceito mais simples de crescimento econômico. Conforme o autor, deve-se pensar em crescimento como o aumento da produção real, mais precisamente do fluxo de renda, portanto exprimível quantitativamente ao nível do subconjunto econômico especializado. Por outro lado, desenvolvimento é o mesmo fenômeno quando observado a partir da sua repercussão na complexa e diversificada estrutura social e econômica, dada pela divisão do trabalho social, o que inclui o perfil da demanda que é baseado num sistema de valores individuais e coletivos dessa determinada sociedade (FURTADO, 1983). 
Todavia, a teoria tradicional sobre o desenvolvimento se concentrou demasiadamente apenas sobre o crescimento econômico, em questões como acumulação de capital e renda agregada, negligenciando aspectos humanos, como direitos e capacidades dos indivíduos, embora não se possa defender que crescimento não importe (SEN, 1983).

Portanto, a noção de crescimento está compreendida no conceito de desenvolvimento que se refere à evolução do conjunto de uma estrutura social e econômica complexa, no sentido da satisfação das múltiplas necessidades dessa coletividade. A referida complexidade da estrutura do conjunto econômico é permanentemente influenciada pela multiplicidade de fatores sociais e institucionais (FURTADO, 1983).

Para Furtado, a hipótese de crescimento sem desenvolvimento constitui "uma construção mental sem correspondência na realidade" e quanto mais complexa a divisão social do trabalho mais se aplica essa observação (FURTADO, 1983: 78).

Conforme a concepção furtadiana, as decisões quanto à destinação da renda para o consumo (teoria do comportamento do consumidor), à transformação de fatores produtivos em outro conjunto de recursos (teoria da produção), e à alocação diferida no tempo do produto que não é destinado ao consumo, e que serve para expandir a capacidade de produção, constituem matéria da teoria do desenvolvimento (FURTADO, 1983).

No centro do conceito de desenvolvimento está a noção de economia nacional, que engloba os sistemas político e econômico. Portanto, a análise da estrutura e funcionamento de uma economia nacional deve levar em conta as decisões sobre tais dimensões de análise (FURTADO, 2008).

$\mathrm{Na}$ ótica furtadiana, ambos os sistemas são condicionados por decisões políticas a partir de estruturas de poder, como a propriedade da terra, o controle da riqueza acumulada, do excedente do produto social, do acesso à tecnologia, do fluxo de informações. Tais fatores estão na base da produção e da acumulação social e determinam o perfil da demanda do consumo privado. Esse perfil, por sua vez, é condicionado por fatores institucionais e culturais. Assim, faz-se necessário conhecer as estruturas de poder para entender o sistema econômico e identificar as estruturas sociais para compreender as decisões políticas (FURTADO, 1983, 2008).

Um sistema de poder é a capacidade que tem um grupo social de gerar e/ou se apropriar do excedente social engendrado a partir do aumento da produtividade do 
trabalho, que é fruto do progresso técnico, além do nível de subsistência dessa coletividade. O controle do excedente, fundamento do processo do desenvolvimento, pode se dar pelo controle da criatividade artística, científica ou tecnológica, bem como pelo controle e manipulação do fluxo de informações, e a sua reprodução contínua possibilita a estabilidade das estruturas sociais no tempo (FURTADO, 1977, 1983, 2008).

Exemplo da capacidade de um grupo controlar o excedente social é o utilizado por Furtado na análise da dinâmica da economia primário-exportadora brasileira, da qual derivou o conceito de "socialização de perdas". Por tal mecanismo, nos momentos de alta cíclica, o setor exportador nacional retinha o aumento da produtividade econômica, por outro lado, quando os preços do café caíam, depreciava-se a moeda brasileira, elevando-se os preços dos bens importados, cuja pauta na época - fins do século XIX e início do XX, consistia, em sua maioria, em alimentos e tecidos, ou seja, afetando negativamente a grande massa consumidora, em especial a população urbana. A concentração de riqueza nas mãos do setor exportador nos momentos de alta não era compensada nos momentos de contração de renda (FURTADO, 2005, 2014).

Para o autor:

[...] a mola do processo de desenvolvimento são [os] padrões de comportamento [dos] agentes econômicos, [tais como os esforços que os capitalistas fazem para manter sua participação na renda ou o empenho dos assalariados em aumentar sua parcela na distribuição da renda, o processo de introdução e difusão de inovações e a orientação do progresso técnico], que estão em condições de exercer uma forma de poder, isso é, de modificar a conduta previsível de outros agentes, ou de alterar relações estruturais de forma a frustrar as expectativas de outros agentes (FURTADO, 1983: 104).

Portanto, o desenvolvimento deve ser entendido como a elevação do nível material de vida, que consiste nas transformações das formas de produção e das estruturas sociais, tendo como pano de fundo o equilíbrio de forças que prevalece nessa sociedade. O principal fator condicionante das escalas de preferência de uma coletividade é a distribuição de renda, a partir do excedente gerado socialmente (FURTADO, 1983). 
São os elementos institucionais que condicionam a organização da produção e a distribuição da renda. A estrutura do sistema econômico se funda nesses elementos institucionais, nos recursos naturais, em dados técnicos e em padrões de comportamento de uma coletividade, e a relativa estabilidade desses permite que as variáveis econômicas apresentem uniformidade, que pode ser objeto de análise. Concluindo, desenvolvimento é um problema de acumulação, de progresso técnico e da expressão de valores de uma coletividade (FURTADO, 1983).

Por outro lado, o que caracteriza o subdesenvolvimento é a disparidade entre o dinamismo da demanda, centrada em padrões de consumo oriundos dos países centrais, e o atraso na acumulação reprodutiva nas nações periféricas, causado pela forma de inserção dessas no sistema de divisão internacional do trabalho. A visão simplificada do pensamento econômico prevalecente considerava a difusão da civilização industrial apenas sob a ótica da acumulação, ou seja, importavam somente aspectos relativos às forças produtivas, à dominação do meio e à utilização eficaz dos escassos recursos econômicos (FURTADO, 1984).

Tal processo de acumulação modernizante não proporcionava a superação do subdesenvolvimento na periferia, isto é, não transformava as estruturas sociais de forma a redistribuir renda e a modificar a destinação do excedente social. Mais, engendrava o subemprego, a manutenção da dominação tradicional e a dependência tecnológica (FURTADO, 1972b, 1984). Então, era necessária uma teoria do subdesenvolvimento para fazer frente a essas malformações estruturais.

Para Celso Furtado, a industrialização é a principal via para superar o subdesenvolvimento. No entanto, a industrialização somente produz desenvolvimento autônomo e autossustentado, quando é orientada para o mercado interno, cujo componente principal é a massa salarial, e desde que seja conduzida por uma estratégia de nação. No entanto, Furtado adverte que a superação do desenvolvimento via mercado interno, que se constitui no caminho mais curto para superar a heterogeneidade social (FURTADO, 1999), não pode ser confundida com o fechamento da economia, a não ser “por ignorância ou má fé” (FURTADO, 2001: 80). Assim, um projeto de desenvolvimento que se assente em tais bases promove, além de crescimento econômico, bem-estar social, liberdade, cidadania e integração nacional.

Contudo, como mencionado acima, dentre as várias mudanças em curso desde a década de 1980, cabe destacar, segundo Arend (2013), que o Brasil tem apresentado queda permanente da participação do emprego industrial e da participação da indústria 
no PIB, confirmando a ocorrência do fenômeno da desindustrialização precoce. ${ }^{5} \mathrm{O}$ Brasil não somente está se desindustrializando frente aos países desenvolvidos, considerados na literatura especializada como economias que alcançaram a maturidade industrial ainda nos anos 1970 e, portanto, que vêm passando por um processo considerado natural, com elevado nível de renda per capita. O país também se desindustrializa em relação às economias em desenvolvimento consideradas pouco dinâmicas, como as da Oceania e da África. ${ }^{6}$

Assim, nessa quadra de desindustrialização precoce, o desenvolvimento, então, deve ser entendido a partir de um processo global: a transformação da sociedade ao nível dos meios e dos fins. Aquele é relacionado ao processo de acumulação e de ampliação da capacidade produtiva, da visão social do trabalho e da cooperação, com isso elevando a produtividade do trabalho, bem como a partir da introdução de novos produtos e da diversificação do consumo.

Já os fins são dizentes com a apropriação e a configuração do produto social, bem como com a estratificação social e com os mecanismos de poder e de dominação, e com a criação de valores (morais, estéticos, artísticos, religiosos etc.).

Por outro lado, o desenvolvimento tem assento em dois processos de criatividade: o primeiro, relativo à técnica que visa dotar o homem de capacidade de ação; o segundo, refere-se aos valores substantivos a partir dos quais o homem enriquece seu patrimônio existencial. Para Furtado, está implícito na criatividade um elemento de poder e o agente que o exerce se coloca na posição de motor do sistema econômico. Não há como falar em desenvolvimento sem a liberação da criatividade do povo. Assim, o desenvolvimento deve fundar-se na realização das potencialidades humanas e tem como tema central uma reflexão sobre a cultura nacional (FURTADO, 1994a).

Portanto, não há que se falar em desenvolvimento se esse for apenas dos meios, dos instrumentos relacionados à acumulação de capital, do desenvolvimento das forças produtivas que não levam em conta as especificidades dos nossos recursos, guiado por

\footnotetext{
${ }^{5}$ Na mesma linha Oreiro e Feijó (2010) e Morceiro e Guilhoto (2019). Por outro lado, há estudos como os de Bonelli e Pessoa (2010) e Bonelli, Pessoa e Matos (2013), que entendem que os dados não corroboram a desindustrialização precoce ou prematura do país. Para uma discussão a respeito das possibilidades de superação da crise no setor industrial do país a partir do papel da inovação e das novas tecnologias veja, por exemplo, Santos (2018).

${ }^{6}$ O Brasil apresentou uma taxa de crescimento industrial acumulada no período 1980-2010 de apenas $56 \%$, enquanto que a média dos países do mundo foi de $140 \%$ e a das economias em desenvolvimento foi de 509\% (AREND, 2013).
} 
um padrão de consumo sofisticado originado de fora que, embora possibilite a capacidade de ação da sociedade, não leva em conta os fins substantivos da coletividade em termos da realização das suas potencialidades.

Para Furtado, o desenvolvimento efetiva-se realmente quando o homem se empenha em "enriquecer seu universo de valores" e quando a acumulação conduz à criação de valores que se difundem na coletividade (FURTADO, 1984). Para o autor, a dimensão oculta do desenvolvimento é a criação desses valores substantivos e a faculdade que uma sociedade tem em ordenar a acumulação em função das prioridades definidas por ela mesma é chamada de desenvolvimento endógeno (FURTADO, 1984).

Esse desenvolvimento se alicerça a partir da criatividade em termos dos fins, utilizando tecnologia compatível com a preservação da autonomia na definição coletiva dos valores sociais e não com base na "mundialização", fruto da lógica dos mercados e que está na base da difusão da civilização industrial. Segundo Furtado, o desenvolvimento endógeno seria possível mesmo partindo de um baixo nível de acumulação e de estruturas malformadas oriundas do referido processo de mundialização (FURTADO, 1978, 1984).

Para Furtado há três modelos de políticas voluntaristas de endogeneização do desenvolvimento: a) a coletivização dos meios de produção; b) a satisfação de um conjunto de necessidades básicas da população que permite modificar o perfil de distribuição da renda, mas tal modelo depende de uma decisão política nesse sentido; e, c) o aumento do grau de autonomia externa por meio do favorecimento de setores com capacidade competitiva que produzam efeitos de encadeamento vindo a formar o mercado interno (FURTADO, 1984).

Os três modelos apresentam problemas para Furtado como, por exemplo, a coletivização dos meios de produção que enfrenta dificuldades de acesso à tecnologia e ao financiamento internacional, e o aumento do grau de autonomia externa dada a dificuldade em identificar as bases sociais de uma estrutura de poder que leve adiante esse modelo (FURTADO, 1984). No entanto, segundo Herrlein Júnior (2014: 24), o modelo que via no atendimento das necessidades básicas da coletividade o meio para endogeneizar o desenvolvimento e alcançar a homogeneização social era “[...] de fato o único caminho compatível simultaneamente com o mercado e com a democracia, podendo ser fundamentado numa ética da igualdade de oportunidades".

Se almeja com a endogeneização do desenvolvimento, portanto, aumentar a autonomia na alocação das atividades econômicas, a redução das desigualdades sociais 
e o enriquecimento da cultura nacional, contribuindo para a criatividade numa sociedade cada vez mais globalizada, de forma a preservar a própria identidade da coletividade. Com essas transformações estruturais seria possível alcançar a homogeneização social.

Contudo, Furtado adverte que o mundo real exige o cumprimento de algumas condições necessárias: a) aumentar a autonomia nas relações exteriores visando a uma maior apropriação nacional do excedente social; b) contar com estruturas de poder que evitem a canalização de todo o excedente para o processo de "modernização" de forma a aumentar o nível da poupança nacional; c) incentivar certo nível de descentralização das estruturas econômicas de forma a utilizar o potencial produtivo nacional; e, d) promover estruturas sociais que abram espaço à criatividade levando em conta a cultura nacional, gerando forças preventivas e corretivas dos processos de concentração de poder (FURTADO, 1984).

$\mathrm{Na}$ abordagem do autor:

Somente a criatividade política impulsada pela vontade coletiva poderá produzir a superação desse impasse. Ora, essa vontade coletiva poderá surgir se se der um reencontro das lideranças políticas com os valores permanentes de nossa cultura, cujas raízes estão na massa da população. Portanto, o ponto de partida do processo de reconstrução que temos pela frente terá que ser uma maior participação do povo no sistema de decisões. Assim, o desenvolvimento futuro poderá alimentar-se da criatividade de nosso povo e efetivamente contribuir para a satisfação dos anseios mais legítimos deste (FURTADO, 1984: 30).

Para tanto, um Estado Democrático Desenvolvimentista nos termos propostos por Herrlein Júnior (2014), que avança na proposição furtadiana da atuação estatal, ao dar legitimidade à atuação do Estado, a partir da participação ativa dos membros da coletividade nas estruturas de poder e, com isso, definir os rumos substantivos da sociedade. Assim, o Estado num país periférico, como o Brasil, é central para a promoção do desenvolvimento, estabelecendo centros endógenos de decisão capazes de ordenar o processo acumulativo em função de prioridades definidas pela própria sociedade. 


\subsection{O papel do Estado na promoção do desenvolvimento endógeno}

Furtado fez uma análise da difusão da civilização industrial a partir de países centrais, como a Inglaterra e a Alemanha, e também analisou o desenvolvimento de economias periféricas como, por exemplo, China e Rússia, dentre outros (FURTADO, 1978, 1983, 2008). Evidenciou o papel central que o Estado teve para a promoção do desenvolvimento econômico, na mesma linha que Evans (1993), Chang (2004) e Acemoglu e Robinson (2012) fizeram muito tempo depois. Para esses autores, o Estado é condição necessária para o desenvolvimento de uma sociedade por meio de mudanças estruturais.

Por outro lado, Douglass North, representante da Nova Economia Institucional, passou a ser referência do pensamento econômico tradicional para o estudo do desenvolvimento das economias no longo prazo, condicionadas pela formação e evolução de suas instituições, a partir de um Estado que estabelece e garante os direitos de propriedade (NORTH, 1990). Todavia, depreende-se da leitura da obra furtadiana que o Estado tem uma função de maior relevo para o desenvolvimento, para a transformação das estruturas sociais e econômicas, do que o papel atribuído por Douglas North.

Conforme Furtado (1977, 1983), é um erro pensar na ação do Estado somente via alocação dos recursos que arrecada ou pela forma que capta tais fundos, dessa forma podendo modificar o perfil da demanda como, por exemplo, equalizando os padrões de consumo entre as minorias dominantes e a massa da população, bem como no financiamento de tais padrões de consumo (pelo lado da demanda). Da mesma forma, age estruturando o sistema produtivo de acordo com os objetivos nacionais e as prioridades sociais, na apropriação e redistribuição do excedente, na descentralização da riqueza, e na coordenação das decisões econômicas (pelo lado da oferta). Atua, igualmente, fomentando o desenvolvimento da pesquisa científica e tecnológica nos países periféricos em função de suas prioridades coletivas.

O Estado deve atuar, também, modificando o padrão de desenvolvimento, tendo em vista o custo crescente em termos de recursos não renováveis que são suportados pela sociedade: aumentando o uso de formas coletivas de consumo, reduzindo a parcela de renda disponível para o consumo privado, direcionando o processo de inovação 
tecnológica em prol de métodos mais eficazes, induzindo alterações dos padrões de consumo e, até mesmo, diminuindo o ritmo da introdução de novos produtos. Em suma, o Estado deve atuar subordinando os critérios econômicos aos valores sociais substantivos definidos num projeto de civilização nacional (FURTADO, 2008).

$\mathrm{Na}$ mesma linha, Keynes entendia que o Estado tem por objetivo final o desenvolvimento econômico, e deve ser visto como um "space of conciliation between democratic will and technocratic ruling” (TERRA, FERRARI, FONSECA, 2020: 2), regulando a atividade econômica, reduzindo o desemprego e a distribuição de renda e riqueza.

Segundo Bresser-Pereira (2008), Celso Furtado defendia a intervenção do Estado na economia não de forma radical, mas de forma moderada, pautado pelos interesses da sociedade e mediante atuação democrática. O Estado deveria anteceder e regular o mercado. ${ }^{7}$ Por outro lado, esse Estado não deve atuar livremente, sem controle algum, eis que é fonte potencial de deturpações que afetam o projeto de desenvolvimento da sociedade; sua atuação precisa ser fiscalizada, eis que sofre pressão de setores anacrônicos da sociedade, de setores ligados à grande empresa internacional e ao capital financeiro internacional, que buscam cooptar o controle do poder estatal e dos recursos públicos (CEPÊDA, 2010).

Bresser-Pereira (2006) afirma que as políticas neoliberais adotadas a partir do final dos anos 1980 falharam em promover a estabilização macroeconômica e o crescimento na América Latina, abrindo espaço para o surgimento do novo desenvolvimentismo assentado em bases keynesianas e na teoria econômica do desenvolvimento. Esse modelo se apoia num tripé: 1) estabilidade macroeconômica; 2) instituições que fortaleçam o Estado e o mercado e por um conjunto de políticas econômicas que constituam uma estratégia nacional de desenvolvimento; e, 3) promoção da poupança interna, do investimento e da inovação empresarial.

Contudo, não é objetivo desse artigo revisitar o papel do Estado Desenvolvimentista na Ciência Econômica, mas inseri-lo dentre de um arcabouço teórico que promova o desenvolvimento endógeno. ${ }^{8}$ Basta referir que, no Século XX, tal

\footnotetext{
7 Na visão de Plínio de Arruda Sampaio Júnior (1999) a crença furtadiana de que é possível encontrar soluções para os impasses da dependência sem romper com o regime capitalista, torna a análise do subdesenvolvimento latino-americano bastante limitada. Contudo, a visão de Furtado é compartilhada por Keynes que via a regulação da atividade econômica pelo Estado como indispensável para o desenvolvimento do capitalismo (TERRA, FERRARI, FONSECA, 2020).

8 Para saber mais sobre o Estado Desenvolvimentista veja Evans (1993), Chang (1999) ou Fonseca (2014). Esse autor, por exemplo, estabelece o núcleo comum ou core do conceito: 1) a existência de um
} 
Estado foi fundamental para o avanço do desenvolvimento econômico dos países do leste asiático (CHANG, 2004) e no Brasil para a industrialização via processo substitutivo de importações (FONSECA, 2014). ${ }^{9}$

Por outro lado, o Estado Democrático Desenvolvimentista (EDD) é caracterizado por funções desenvolvimentistas redefinidas, bem como por instituições transformadas que podem viabilizar o desenvolvimento endógeno, indo além do desenvolvimento capitalista e do Estado Desenvolvimentista do Século XX (HERRLEIN JÚNIOR, 2014).

Na abordagem de HERRLEIN JÚNIOR (2014: 40):

A busca do desenvolvimento endógeno destaca a perspectiva inovadora da função de construção de instituições. O EDD corresponde a um novo padrão de Estado, teoricamente concebível e historicamente plausível. Portanto, guarda semelhanças com as formas históricas conhecidas do Estado capitalista, mas não corresponde propriamente ao ED clássico, tampouco ao Estado de bem-estar social e ao Estado regulatório liberal, formas históricas pouco adequadas para as funções do Estado na promoção do desenvolvimento endógeno.

Mais do que redefinir a atuação do Estado, deve-se envolver a sociedade civil em um projeto socioeconômico que resinifique o desenvolvimento de forma consciente para a superação do subdesenvolvimento. A maior participação da sociedade deve se dar por meio do exercício da cidadania e do controle social, via democracia participativa que, por meio consensual, estabelece os fins da coletividade em termos do que é necessário, desejável ou possível, bem como define os métodos e instrumentos utilizados para consecução dos fins estabelecidos. Nesse sentido, a democracia é a "(...) melhor forma de conduzir o projeto de desenvolvimento e a consolidação da Nação" (CEPÊDA, 2003: 11).

Nas palavras de Furtado (1984: 12; grifos nossos), “nenhum avanço real é exequível sem desenvolvimento político, sem democratização substantiva, sem a

projeto deliberado ou estratégia tendo como objeto a nação e seu futuro; 2) a intervenção consciente e determinada do Estado com o propósito de viabilizar o projeto; 3) a industrialização, como caminho para acelerar o crescimento econômico, a produtividade e a difusão do progresso técnico, inclusive para o setor primário.

9 Para uma discussão recente sobre o desenvolvimentismo na economia brasileira veja, por exemplo, Fonseca, Cunha e Bichara (2013) e Fonseca, Arend e Guerrero (2018). 
presença organizada na esfera política de amplos segmentos da sociedade civil, particularmente da massa trabalhadora. Nosso real atraso é político e não econômico”.

\section{Espaço para a utopia}

Tomando emprestado o sentido proposto de Mannheim (1968), “em consciente oposição à definição usual” de ser algo em princípio irrealizável, precisa-se de uma utopia que nos leve adiante, que questione as possibilidades do presente, de forma a orientar o futuro, moldando a realidade histórica, em constante evolução. Nesse sentido, "[e]quivoca-se quem pretende que já não existe espaço para a utopia" (FURTADO, 2002b: 7), há que se intervir na realidade social concreta, comprometendo-se com fazer o histórico.

Assim, para vencer o subdesenvolvimento, os países periféricos precisam resolver seus problemas estruturais. Para tanto, a ação política é fundamental e deve ser orientada por um projeto nacional, baseado nos valores fundamentais da cultura de cada sociedade. Nesse sentido, o Estado se constitui na instituição essencial para fazer esse enfrentamento de forma a transformar qualitativamente a sociedade alcançando, assim, a homogeneização social (FURTADO, 1999, 2002a).

A ação estatal deve promover o desenvolvimento endógeno de forma a enriquecer a cultura em suas múltiplas dimensões, preservando a identidade nacional, estimulando a atividade criativa da cultura da sociedade, não só por meio das manifestações artísticas, mas também via desenvolvimento de técnicas eficazes específicas adaptadas à própria condição social, à disponibilidade de recursos e à capacidade de financiamento.

A saída é descobrir o caminho para a criatividade ao nível dos fins, preservando os processos autônomos de decisão para a definição dos valores substantivos da sociedade. Criatividade é liberdade e, conforme Furtado (1978), a única forma autêntica de liberdade é a política.

Para tanto, e tendo por base ensinamentos de Celso Furtado (1964, 1978, 1999, 2001 2002b) de que o objetivo da ciência é produzir guias para ação prática e que a dinamização de mercado interno é o caminho mais curto para o desenvolvimento, 
elencam-se a seguir algumas medidas de política que podem trazer um novo horizonte de possibilidades vindo a contribuir para a homogeneização social em nossa sociedade:

- defesa intransigente e promoção do regime democrático e, em especial, da democracia participativa como um instrumento fundamental para a superação dos impasses do subdesenvolvimento, via processos endógenos de desenvolvimento, de forma que as forças produtivas se desenvolvam coerentemente com os padrões de consumo, a partir de uma estratégia nacional da sociedade;

- via autodeterminação política, internalizar o controle sobre o excedente social buscando alcançar a homogeneização social;

- $\quad$ reverter o processo de concentração patrimonial e de renda;

- $\quad$ enfrentamento da fome e da subalimentação;

- atacar o atraso nos investimentos no fator humano, seja no acesso ou na melhoria da qualidade dos serviços, em educação, saúde, moradia e segurança: a miséria da maior parte do povo é a contrapartida do "hiperconsumo" da minoria;

- promover o processo criativo e o desenvolvimento endógeno e, assim, enriquecer o universo de valores da nossa sociedade;

- fomentar o desenvolvimento de pesquisa científica e tecnológica em função das prioridades coletivas; e,

- $\quad$ conciliar o processo de globalização, de mundialização, imposto pela lógica dos mercados, que restringiu o campo de atuação do Estado, em prol do mercado interno e da criação de empregos, diminuindo a vulnerabilidade externa, além de modificar a pauta de importações visando a aquisição de tecnologia de forma consentânea com a disponibilidade de fatores produtivos e padrões de consumo nacionais.

\section{Conclusões}

Dada a construção teórica ímpar e o brilhantismo de sua obra, Celso Furtado deve "ser fonte de inspiração e ponto de partida" (OLIVEIRA, 2001: 3) e, no ano que se completa o centenário do seu nascimento, nada mais atual do que seu ensinamento de que, em épocas de crise, o primeiro dever de um cientista é abandonar as explicações 
cômodas oriundas de doutrinas baseadas no reducionismo econômico que não levam em conta os problemas que corroem o organismo social.

Ao revisitar a produção intelectual de Celso Furtado depreende-se a dinâmica do desenvolvimento como um processo global de meios e fins substantivos estabelecidos consensualmente pela sociedade como um projeto nacional. Um projeto nacional deliberado de forma autônoma - uma estratégia para a nação, que vise uma sociedade mais justa, plural, igualitária e que necessita, para isso, da atuação política via um Estado Democrático Desenvolvimentista (HERRLEIN JÚNIOR, 2014).

Continua válida, portanto, a afirmação de Furtado (1983) de que a consciência política da situação de subdesenvolvimento e a tomada autônoma de decisões, com base em objetivos nacionais e prioridades sociais genuínos, é condição para alcançar o desenvolvimento, modificando a sociedade a partir de dentro, de centros dinâmicos próprios, transformando as estruturas sociais e econômicas para agir de forma mais flexível no mundo globalizado.

Toda atenção a sua obra deve ser dada, não pelo desgaste e pelo pequeno poder explicativo da teoria dominante, mas por conta das barreiras ao desenvolvimento, da impossibilidade de promover a homogeneização social, de impedir a devastação dos recursos naturais e de reverter a degradação social. Há que se apresentar propostas para a superação dos problemas da realidade, tarefa de uma ciência social como a Economia, que transforme a sociedade e construa o futuro em termos das potencialidades humanas nacionais. Assim, o conhecimento deve ser balizado pelos fins sociais, não somente visando à satisfação material, mas também em termos dos valores substantivos, superando esquemas de privilégios e de dominação social (FURTADO, 1979, 1999).

Mesmo que se diga que a obra de Furtado não seja um todo homogêneo, eis que os conceitos foram sendo constantemente reformulados, a partir do próprio método que utiliza para perceber a estrutura social como um processo dinâmico em permanente desenvolvimento, não se pode negar a lógica e o rigor metodológico do autor. Mais, depreende-se uma postura metodológica interdisciplinar dos diversos saberes, como a Sociologia, a História, a Ciência Política e a Filosofia, não se atendo apenas ao saber econômico.

Talvez o maior legado do cientista Celso Furtado tenha sido pensar e agir para influenciar os rumos da sociedade brasileira, por meio de uma ação política em prol de um projeto de desenvolvimento nacional, preservando os valores fundamentais específicos da nossa cultura. 
Para Furtado, os cientistas devem ter responsabilidade social, por meio da definição de rumos e da assunção de responsabilidades. Quanto maior a autocrítica e consciência de responsabilidade social do cientista, mais a ciência poderá avançar e, com isso, mudar a realidade, superando problemas estruturais que limitam a potencialidade dos países subdesenvolvidos. Ou como defendia Myrdal (1968), liberando não só o pensamento dos próprios preconceitos, mas, sobretudo, os da sociedade. Para isso, deve-se, até mesmo, escrever um "anti-livro acadêmico" como Furtado se refere a sua obra Criatividade e Dependência na Civilização Industrial (1978).

Há espaço sim para utopia. Mas, para isso, é necessário "pensar por conta própria e ultrapassar certos limites" com "imaginação e coragem para arriscar em caminhos por vezes incertos". Não basta se munir de técnicas quantitativas e instrumentos eficazes de mensuração de variáveis econômicas; "há que se atuar de forma consistente no plano político, assumir a responsabilidade de interferir no processo histórico, orientar-se por compromissos éticos" (FURTADO, 2002b: 6).

Há consideráveis desafios em termos econômicos, políticos e, especialmente, sociais para o Brasil e encontrar saídas viáveis para seu desenvolvimento em termos substantivos deve ser objeto de atenção da sociedade, da academia e dos formuladores de políticas. Parafraseando Celso Furtado, devemos tornar o futuro não uma opção, mas destino de um projeto alternativo de nação, de sociedade, que não prescinde do aumento da participação e do poder popular nos centros de decisão do país.

\section{Referências bibliográficas}

ACEMOGLU, D.; ROBINSON, J. A. (2012). Por que as nações fracassam: as origens do poder, da prosperidade e da pobreza. Rio de Janeiro: Elsevier.

ALMEIDA FILHO, N. (2008). A utopia pragmática de Celso Furtado: o futuro possível. Revista Economia Ensaios, Uberlândia, v. 22, n. 2.

AREND, M. (2013). A industrialização do Brasil ante a nova divisão internacional do trabalho. Instituto de Pesquisa Econômica Aplicada (IPEA). Subprograma de Pesquisa para o Desenvolvimento Nacional - PNPD. Projeto/Pesquisa: Agenda Desenvolvimentista e sua Inserção Global.

BIELSCHOWSKY, R. (1998). Evolução das ideias da CEPAL. Revista da CEPAL, Número Extraordinário, Santiago do Chile, out.

BONELLI, R.; PESSOA, S. (2010). Desindustrialização no Brasil: um resumo da evidência. Centro de Desenvolvimento Econômico, Ibre-FGV, TD 7 de maio de.

BONELLI, R.; PESSOA, S.; MATOS, S. (2013). Desindustrialização no Brasil: fatos e interpretação. In: BACHA, E. O futuro da indústria no Brasil: desindustrialização em debate. Rio de Janeiro: Civilização Brasileira, p. 201-225. 
BRESSER-PEREIRA, L. C. (2001). Método e paixão em Celso Furtado. In: BRESSER-PEREIRA, L. C., REGO, J. M. (org.). A Grande Esperança em Celso Furtado. São Paulo: Editora 34, p. 19-43.

(2006). O novo desenvolvimentismo e a ortodoxia convencional. São Paulo em Perspectiva, v. 20, n. 1, p. 5-24.

. (2008). Celso Furtado e a teoria econômica. In: FURTADO, C. Economia do desenvolvimento: curso ministrado na PUC-SP em 1975. Rio de Janeiro: Contraponto: Centro Internacional Celso Furtado. p. 225-246. (Arquivos Celso Furtado).

CANO, W. (2015). Principais contribuições de Celso Furtado sobre a história econômica do Brasil e o período recente. Cadernos do Desenvolvimento, Rio de Janeiro, v. 10, n. 17, p.128-143, jul.-dez.

CEPÊDA, V. A. (2003). O pensamento político de Celso Furtado: desenvolvimento e democracia.

Disponível

em: <http://www.centrocelsofurtado.org.br/arquivos/image/201108311541490.CEPE DA_O_pensamento_pol\%C3\%ADtico_de_CF.pdf >.Acesso em: 25 jun. 2019.

- (2010). O lugar da teoria do subdesenvolvimento no pensamento de Celso Furtado. In: CORSI, F. L., CAMARGO, J. M. (org.). Celso Furtado: os desafios do desenvolvimento. São Paulo: Cultura Acadêmica, p. 137-160.

CHANG, H-J. (1999). The economic theory of the developmental state. In: WOOCUMINGS, M. (Ed.). The developmental State. Ithaca, New York: Cornell University Press.

(2004). Chutando a escada: a estratégia do desenvolvimento em perspectiva histórica. São Paulo: Editora UNESP.

EVANS, P. (1993). O Estado como problema e solução. Lua Nova: Revista de Cultura e Política, n. 28-29, p. 107-157, abr. Disponível em: <https://dx.doi.org/10.1590/S0102-64451993000100006>. Acesso em: 30 set. 2019.

FONSECA, P. C. D. (2014). Desenvolvimentismo: a construção do conceito. In: CALIXTRE, B.: BIANCARELLI, A. M.; MACEDO CINTRA, M. A. Presente e futuro do desenvolvimento brasileiro. Brasília: IPEA.

FONSECA, P. C. D.; CUNHA, A.; BICHARA, J. (2013). O Brasil na Era Lula: retorno ao desenvolvimentismo?. Nova Economia, v. 23, p. 403-427, mai./ago.

FONSECA, P. C. D.; AREND, M.: GUERRERO, G. (2018). Política econômica, instituições e classes sociais: os governos do Partido dos Trabalhadores no Brasil. Disponível em: 〈http://professor.ufrgs.br/pedrofonseca/publications >. Acesso em: 11 jun. 2019.

FURTADO, C. (1964). Dialética do desenvolvimento. Rio de Janeiro: Fundo de Cultura. (Perspectivas do Novo Tempo).

(2013 [1972a]). Aventuras de um economista brasileiro. In: FREIRE D’AGUIAR, R. (org.). Essencial Celso Furtado. São Paulo: Penguin/Companhia das Letras, 2013.

(1972b). Análise do "modelo" brasileiro. Rio de Janeiro: Civilização Brasileira.

(1974). O mito do desenvolvimento econômico. Rio de Janeiro: Paz e Terra.

. (1977). Prefácio à nova economia política. 2 ed. Rio de Janeiro: Paz e Terra. (Coleção O Mundo de Hoje).

(1978). Criatividade e dependência na civilização industrial. Rio de Janeiro: Paz e Terra.

. (2013 [1979]). Ciência para quê e para quem? In: FREIRE D’AGUIAR, R. (org.). Essencial Celso Furtado. São Paulo: Penguin/Companhia das Letras. 
(1981). Pequena introdução ao desenvolvimento: enfoque interdisciplinar. 2 ed. São Paulo: Companhia Editora Nacional.

- (1983). Teoria e política do desenvolvimento econômico. São Paulo: Abril Cultural. (Coleção Os Economistas).

- (1984). Cultura e desenvolvimento em época de crise. Rio de Janeiro, Paz e Terra.

(1992). O subdesenvolvimento revisitado. Economia e Sociedade. UNICAMP, v. 1, n.1, p. 5-19.

(1994a). A superação do subdesenvolvimento. Economia e Sociedade. UNICAMP, v. 3 n. 1, p. 37-42.

(1994b). A invenção do subdesenvolvimento. [S.n.]: Porto Alegre, 03 nov. 1994, p. 1-9. (Aula magna proferida por ocasião do recebimento do Título de Doutor Honoris Causa da Universidade Federal do Rio Grande do Sul).

(1999). O longo amanhecer: reflexões sobre a formação do Brasil. Rio de Janeiro: Paz e Terra.

(2000 [1961]). Desenvolvimento e subdesenvolvimento. In: BIELSCHOWSKY, R. (org.). Cinquenta anos de pensamento na Cepal. Rio de Janeiro: Record.

(2001). O capitalismo global. 5 ed. São Paulo: Paz e Terra.

- (2002a). Em busca de novo modelo: reflexões sobre a crise contemporânea. Rio de Janeiro: Editora Paz e Terra.

(2002b). Metamorfoses do capitalismo. [S.n.]: Rio de Janeiro, 02 dez, p. 1-7. Disponível em: 〈http://www.redcelsofurtado.edu.mx/archivosPDF/furtado1.pdf>. Acesso em: 15 ago. 2019.

. (2005). Formação econômica do Brasil. 32 ed. São Paulo: Companhia das Letras. (2008). Economia do desenvolvimento: curso ministrado na PUC-SP em 1975.

Rio de Janeiro: Contraponto: Centro Internacional Celso Furtado. (Arquivos Celso Furtado).

. (2014). Obra autobiográfica. Rio de Janeiro: Companhia das Letras.

HERRLEIN JR., R. (2014). A construção de um estado democrático para o desenvolvimento no Século XXI. Rio de Janeiro: Ipea, fev. (Texto para discussão, n. 1935).

MANNHEIM, K. (1960). Libertad, poder y planificacion democrática. Cidade do México: Fondo de Cultura. . (1968). Ideologia e utopia. Rio de Janeiro: Zahar Editores.

MORCEIRO, P. C.; GUILHOTO, J. J. M. (2019). Desindustrialização setorial e estagnação de longo prazo da manufatura brasileira. São Paulo: USP-NERUS, TD Nereus 01.

MYRDAL, G. (1968). Teoria econômica e regiões subdesenvolvidas. Rio de Janeiro: Saga.

NIEDERLE, P. A., RADOMSKY, G. F. W. (org.) (2016). Introdução às teorias do desenvolvimento. Porto Alegre: Editora da UFRGS.

NORTH, D. C. (1990). Institutions, institutional change and economic performance. Cambridge: Cambridge University Press.

OLIVEIRA, F. (2000). Subdesenvolvimento: fênix ou extinção? In: TAVARES, M. C.. Celso Furtado e o Brasil. São Paulo: Editora Fundação Perseu Abramo. . (2001). Um Republicano Exemplar. In: ABRAMOVAY, R. et al. (org.). Razões e ficções do desenvolvimento. São Paulo: Editora Unesp/Edusp.

OREIRO, J. L.; FEIJÓ, C. A. (2010). Desindustrialização: conceituação, causas, efeitos e o caso brasileiro. Revista de Economia Política, vol. 30, n. 2 (118), p. 219-232, abr.-jun. 
PREBISCH, R. (2000 [1949]). O desenvolvimento econômico da América Latina e alguns de seus problemas principais. In: BIELSCHOWSKY, R. (org.). Cinquenta anos de pensamento na Cepal. Rio de Janeiro: Record.

ROSTOW W. W. (1964). Etapas do desenvolvimento econômico (um manifesto não comunista). 2 ed. Rio de Janeiro: Zahar Editores.

SAMPAIO JÚNIOR, P. A. (1999). Entre a nação e a barbárie. Rio de Janeiro: Vozes.

SANTOS, U. P. (2018). Reestruturação industrial e inovação no Brasil: possibilidades para a retomada do crescimento e do desenvolvimento. In: ANDRADE, M. V.; ALBUQUERQUE, E. M. (Ed.). Alternativas para uma crise de múltiplas dimensões. Belo Horizonte: CEDEPLAR - UFMG, cap. 22.

SEN, A. (1983). Development: Which way now? Economic Journal, vol. 93, Issue 372, December, p. 745-762. Disponível em: 〈http://darp.lse.ac.uk/PapersDB/Sen_(EJ_83).pdf>. Acesso em: 18 out. 2019.

TAVARES, M. C. (2000). Celso Furtado e o Brasil. São Paulo: Editora Fundação Perseu Abramo.

TERRA, F, FERRARI F, FONSECA P. C. D. (2020). Keynes on state and economic development. Review of Political Economy, v. 32, n. 3.

Artigo recebido em 15 de julho de 2020.

Aprovado em 18 de novembro de 2020.

DOI: $10.12957 /$ intellectus.2020.52768 